\title{
Mechanical Treatment of MSWI Fly Ash: A Way Forward to Inhibit PCB Reformation
}

\author{
Ishrat Mubeen ${ }^{1,2}$, Xiaoqing Lin ${ }^{1 *}$, Zhiliang Chen ${ }^{1}$, Alfons Buekens ${ }^{1,3}$, Mi Yan ${ }^{2}$, Shengyong Lu ${ }^{1}$, \\ Dwi Hantoko ${ }^{2}$, Xiaodong $\mathrm{Li}^{1}$, Jianhua Yan ${ }^{1}$ \\ ${ }^{1}$ State Key Laboratory for Clean Energy Utilization, Institute for Thermal Power Engineering, Zhejiang University, \\ Hangzhou 310027, China \\ ${ }^{2}$ Institute of Energy and Power Engineering, Zhejiang University of Technology, Hangzhou 310013, China \\ ${ }^{3}$ Formerly: Chemical Engineering Department, Vrije Universiteit Brussel, 1050 Brussels, Belgium
}

\begin{abstract}
Fly ash from municipal solid waste incinerators has been classified as hazardous waste due to the presence of unintentionally-produced Persistent Organic Pollutants (POPs), with Polychlorinated biphenyls (PCB) being a major group among such POPs. Fly ash can be mechanically (MC) treated to destroy organic pollutants before final disposal or reuse. In this study, model fly ash (MFA) doped with $0.2 \% \mathrm{CuCl}_{2}$ was artificially prepared and subjected to high intensity ball milling for 0 (original sample), 1, 2, 4, and $8 \mathrm{~h}$ of treatment. Furthermore, to explore PCB reformation in the MC treated fly ash, de novo tests were conducted at single reaction time, temperature, and air flow rate. It was found that the sum of $\mathrm{PCB}$, dioxin like PCB, and corresponding International Toxic Equivalent concentrations ( $\sum \mathrm{PCB}, \sum d l-\mathrm{PCB}$ and $\sum \mathrm{I}-\mathrm{TEQ}$, respectively) were greatly reduced both in gas and in solid phase of MFA after $8 \mathrm{~h}$ of treatment. Though chlorination degree successively decreased with prolonged milling, the homologue and isomer signatures of PCB were varied in concentration. Reformation of few isomers was also observed. Results from present study suggest that MC treatment is an effective method to control reformation of pollutants in the long term. However, few suggestions are made for further ongoing research work on MC treatment of fly ash, which are based on surprising results and experimental limitations obtained in this study.
\end{abstract}

Keywords: PCB; Ball milling; De novo formation; Homologues; Isomers; Reformation.

\section{INTRODUCTION}

Polychlorinated biphenyls (PCB) are semi volatile, toxic, stable and persistent chlorinated aromatic compounds, and are classified as Persistent Organic Pollutants (POPs). Most PCB in the environment originiated from technical PCB mixtures or are unintentionally formed in industrial processes (Liu et al., 2013; Praipipat et al., 2013; Praipipat, 2014; UNEP, 2015). Recently, much focus has been given to human exposure to $\mathrm{PCB}$ and particularly to dioxin like PCB ( $d l$-PCB, 12 congeners). These congeners have been assigned toxicity equivalency factors by the World Health Organization because they exhibit dioxin-like toxicity and are classified as carcinogenic to humans (Group 1) by the International Agency for Research on Cancer in 2014 (Jiang et al., 2015).

\footnotetext{
* Corresponding author.

Tel.: +86-571-8795-3385; Fax: +86-571-8795-3385

E-mail address: linxiaoqing@zju.edu.cn
}

Before 1980, because of chemical stability, PCB were produced intentionally as heat exchange fluids and additives in many industrial processes. After a ban on commercial production of $\mathrm{PCB}$, still these compounds are released into the environment by unintentional means. A great public interest to control PCB emissions (generated as by-products) has grown recently, particularly from thermal industries, such as waste incineration (Sakai et al., 2001), primary and secondary copper metallurgical processes and thermal wire reclamation (Nie et al., 2012). Furthermore, a large proportion of unintentionally produced $\mathrm{PCB}$ are released in fly ash from waste incinerators (Sakai et al., 1993; Liu et al., 2016).

MSWI incinerators are one of the highest contributors of $\mathrm{PCDD} / \mathrm{F}$ and $\mathrm{PCB}$ and their precursors into the environment (Guo et al., 2014; Wu et al., 2014; Zhan et al., 2018). To avoid future contamination risks, such fly ash cannot be dumped directly into the landfill without proper treatment (McKay, 2002; Yang et al., 2007). Various studies have shown high concentration of such chlorinated compounds released into the environment from industrial activities and vehicular emissions (Tang et al., 2017; Xing et al., 2017; Zhu 
et al., 2017; Lee et al., 2018; Zhao et al., 2018). Mechanical treatment (MC), as an effective PCDD/F and PCB destruction technique has been employed to control emissions of persistent organic pollutants (Cheruiyot et al., 2019). Various researchers have achieved destruction efficiency of PCDD/F and PCB I-TEQ concentrations more than $90 \%$, via MC treatment under different experimental conditions (Yan et al., 2007; Wang et al., 2012; Cagnetta et al., 2016a; Chen et al., 2018). Compared with microwave irradiation (Liu et al., 2018; Deng et al., 2019) and flotation technique by using surfactants (Liu et al., 2017), MC treatment shows higher destruction efficiency of PCDD/F and PCB.

The principal of $\mathrm{MC}$ treatment reaction depends on the deformation of angles and valence bonds under mechanical stress such as rupture of bonds, bond reformation, oxidation, hydrolysis and other chemical reactions depending on the reaction atmosphere, temperature and matrix. The halogenated pollutants during $\mathrm{MC}$ treatment adsorb on to the solid surface via milling then the activated surface of solid react with pollutant by some pathway like transfer of electrons from radical, ions or organometallic intermediate; oxidation. The milling treatment is advantageous in terms of harmless end products, as if the prolonged milling process is energetic enough, then the organic compounds are reduced to a mixture of graphitic and amorphous carbon, lower molecular hydrocarbon and inorganic halides (Dubinskaya, 1999; Cagnetta et al., 2016b).

Previous work showed that some undesired results have been obtained via MC treatment (Cagnetta et al., 2016a; Mubeen et al., 2017) due to presence of metal chlorides and oxides. These catalysts can induce PCB and PCDD/F regeneration via de novo synthesis under milling treatment conditions. Moreover, most studies focus on direct degradation of POPs via MC treatment, while post treatment analysis of fly ash for the potential reformation of such compounds are limited. Sufficient information on the effects and mechanisms of MC on the suppression of PCB reformation to evaluate long term disposal or reuse of $\mathrm{MC}$ treated fly ash is not available.

This study, as part of our ongoing research on formation of POPs in milled fly ash, presents the results of de novo tests on milled MFA. The aim is to see by how far milling affects reformation of $\mathrm{PCB}$ isomers through mono-CB to deca-CB both in gas and in solid phase. Moreover, after short or longer MC treatment, distribution of all 209 isomer patterns of the PCB were studied and analysed to elucidate the formation and reformation mechanism of PCB. Furthermore, after extensive literature review, it is safe to say that no earlier work has been dedicated to study all the isomers of PCB and their concomitant distribution in $\mathrm{MC}$ treated fly ash.

\section{METHODOLGY}

\section{Preparation and Ball Milling of MFA}

Model fly ash (MFA) sample preparation and ball milling procedures have been described in detail in our previous work (Mubeen et al., 2017). Briefly, required materials were grinded together in a mortar for about $10 \mathrm{~min}$ in the following weight proportions: activated carbon ( $\mathrm{AC} ; 2.5 \mathrm{wt} \%$ ), sodium chloride $(\mathrm{NaCl} ; 10 \mathrm{wt} \% \mathrm{Cl}), 0.2 \mathrm{wt} \%$ copper chloride $\left(\mathrm{CuCl}_{2}\right)$ was added and silica $\left(\mathrm{SiO}_{2}\right)$ formed the balance. Chemical details are available in supplementary materials (S1). An all-dimensional planetary ball mill (QXQM-2, Changsha Tencan Powder Technology Co., Ltd, China) was used for the MC treatment (Chen et al., 2016). The samples were milled for 1, 2, 4, and $8 \mathrm{~h}$. The milling pots, with volume of $500 \mathrm{ml}$, and balls with either $8(2.1 \mathrm{~g})$ or 12 $(7.1 \mathrm{~g}) \mathrm{mm}$ diameter were made of special stainless steel $\left(1 \mathrm{Gr}_{18} \mathrm{Ni}_{9} \mathrm{Ti}\right)$. About $40 \mathrm{~g}$ fly ash samples were charged into each pot, together with equal weight big (10) and small balls (43) under atmospheric conditions, with a ball to powder ratio of $4: 1 \mathrm{wt} / \mathrm{wt}$. After MC treatment, milled fly ash (MFA) was collected for further analysis.

\section{Experimental Setup}

The de novo testing apparatus can be found in supplementary materials (Fig. S1), briefly $2 \mathrm{~g}$ sample of model fly ash (MFA) was placed into a vertical quartz tube (53 cm in length and $5 \mathrm{~cm}$ in diameter) and fixed by means of glass wool. Then the tube was placed for $1 \mathrm{~h}$ in a preheated electric furnace at $300^{\circ} \mathrm{C}$ (optimum temperature to generate PCB) in a flow of $\mathrm{N}_{2}+10 \%$ oxygen $\left(300 \mathrm{~mL} \mathrm{~min}^{-1}\right)$ to simulate the conditions in the post-combustion zone of a MSWI. The glass wool used in our experiments was first rinsed by acetone and then dried at $100^{\circ} \mathrm{C}$. A blank test was also run without sample at similar experimental conditions and after pre-treatment the sample was analyzed for PCB and no compounds were detected in the blank test.

\section{Sample Clean up and Analysis}

Solid (burned MFA) and the gas phase samples (absorbed in toluene and XAD-2 resin) after de novo tests, were collected, and after pre-treatment, were analysed for all 209 isomers from mono- to deca-CB. The analysis was done with HRGC/HGMS on a 6890 Series gas chromatograph (Agilent, USA) and coupled to a JMS-800D mass spectrometer (JEOL, Japan), according to U.S. EPA method (U.S. EPA, 2008). These isomers were quantified by adding a set of mixtures of internal standard solutions applied before extraction, purification and analysis respectively. The recovery rates of each internal standard were in accordance with standard analytical requirements. The toxic equivalency factors (TEFs) of the World Health Organization were used to calculate the toxic equivalence quantity (TEQ) of PCB (Van den Berg et al., 2006).

\section{Analytical Methods}

X-ray fluorescence (XRF) was used to study composition of MFA. Scanning Electron Microscopy (SEM) was employed to reveal surface morphology of the MC treated MFA (Hitachi SU-70). Micromeritics Tristar 3020 instrument was used to get BET (Brunauer-Emmett-Teller) surface area and average particle size. TGA/DSC was performed on fly ash in oxygen (instrument: NETZSCH STA 409 PC/PG). Analysis results are attached in supplementary materials, (Fig. S2, Fig. S3, Table S1, and Table S2). 


\section{RESULTS AND DISCUSSIONS}

\section{Characterization of Model Fly Ash}

XRF analysis results show the composition (cations, anions, and heavy metals) of MFA treated at different times (see Table S1). Silicon and oxygen were the dominant species followed by chlorine and sodium in MFA matrix. Surprisingly, iron $(\mathrm{Fe})$ concentration increased from $0.1 \%$ to $6.0 \%, 8.6 \%, 9.6 \%$, and $9.1 \%$ after $1,2,3,4$, and $8 \mathrm{~h}$ milling, respectively. Copper $(\mathrm{Cu})$, Chromium $(\mathrm{Cr})$, and nickel $(\mathrm{Ni})$ concentration also increased with milling augmentation and hence results show that milling treatment may increase catalytic metals due to wear of steel housing of milling equipment, while calcium $(\mathrm{Ca})$ disappear with longer milling time and zinc ( $\mathrm{Zn}$ ) was not detected in any of the selected samples.

BET surface area increased with time from 2.54 to $6.29 \mathrm{~m}^{2} \mathrm{~g}^{-1}$ at the end of milling treatment, while average particle size- $d p$ decreased from 23.6 to $9.54 \mu \mathrm{m}$ after $8 \mathrm{~h}$ of treatment (see Table S2). Particle surface observed by SEM indicated that MFA consists of many large size particles before MC treatment (Fig. S2(a)) and after $1 \mathrm{~h}$ treatment particles reduced in size (Fig. S2(b)). Large aggregates were found upon further treatment which are formed by sticking small particles together (Figs. S2(c)2(f)). It was observed that further MC treatment did not bring much change in size, but the particles are broken and aggregated repeatedly.

Thermogravimetric analysis data (see Fig. S3) show the evaporation of residual moisture from ambient temperature to $100^{\circ} \mathrm{C}$. According to the DTG profile in Fig. S4(a), a weight loss region occurs between 373 to $409^{\circ} \mathrm{C}$ with a maximum peak value at $393^{\circ} \mathrm{C}$ for $0 \mathrm{~h}$ milled MFA and this is due to thermal release of micro molecular volatile organics and associated with incomplete pyrolysis ( $\mathrm{Hu}$ et al., 2017). In 1, 2, 4, and $8 \mathrm{~h}$ milled samples, (Figs. S3(b)3(e)) this peak disappeared and no significant weight loss region was observed. DSC curve characterized by an exothermal peak, which starts at an extrapolated onset temperature of $\sim 299^{\circ} \mathrm{C}$ and reaches its maximum (peak temperature) at $327^{\circ} \mathrm{C}$, was observed for $0 \mathrm{~h}$ milled sample. Compared to the first sample $(0 \mathrm{~h})$, milled samples had shown just a small bump in DSC curve. As oxidative breakdown of carbonaceous material is necessary to form organic molecules (Stieglitz, 1998), however, milling has reduced average particle size by breaking the fly ash materials, and authors believe that carbon also lost its structure to support de novo formation of PCB to a great extent, probably the Si-O radicals formed from $\mathrm{SiO}_{2}$ attack the carbon skeleton and convert it into amorphous carbon (Zhang et al., 2014).

\section{PCB Output}

After MC treatment for selected hours, the samples are featured with smaller particle size, larger BET surface, less oxidative breakdown of carbon and better dispersion of the reactive catalyst (e.g., $\mathrm{CuCl}_{2}$ ). Therefore, present work was designed to evaluate possible effects of such physicochemical changes in MFA on de novo formation of PCB in the conditions prevailing in the post combustion zone of an incinerator.

For this purpose, a de novo test was conducted under constant conditions: a temperature of $300^{\circ} \mathrm{C}, \mathrm{N}_{2}+10 \% \mathrm{O}_{2}$ $\left(300 \mathrm{~mL} \mathrm{~min}{ }^{-1}\right)$ atmosphere and a reaction time of $1 \mathrm{~h}$. After de novo tests on raw MFA-samples, PCB formation (especially mono- to tetra-CB) was substantial. Fig. 1 shows sum of mono to deca-PCB in gas and solid phase of model fly ash (see Table S3). Milling reduced reactivity of fly ash for formation of PCB after $1 \mathrm{~h}$, surprisingly after $2 \mathrm{~h} \mathrm{PCB}$ concentration increased, which ultimately reduced up to $97 \%$ after $8 \mathrm{~h}$ of milling. $\sum$ PCB observed in gas and solid phase in raw FA was 2353 and $2833 \mathrm{ng} \mathrm{g}^{-1}$, which reduced to $85 \mathrm{ng} \mathrm{g}^{-1}(+96 \%)$ in gas and $83 \mathrm{ng} \mathrm{g}^{-1}(+97 \%)$ in solid phase after $8 \mathrm{~h}$, respectively. Similar trend was observed for $\sum$ I-TEQ concentrations in gas and solid phase at 0,1 , 2, 4, and 8 milling hours and 99\% reduction of $\sum$ I-TEQ of MFA in both phases was achieved after $8 \mathrm{~h}$ (see Table 2).

In our previous work on MFA milling, reformation in terms of total output of $\mathrm{PCDD} / \mathrm{F}$ and $d l$-PCB, as well as erratic reformation of certain isomers (e.g., penta-CB \#123) after $8 \mathrm{~h}$ milling without any additive have been observed in gas phase (Mubeen et al., 2017). Similarly, unexpected results were obtained by Cagnetta et al. (2016): after $4 \mathrm{~h}$ milling of secondary copper smelting fly ash they got $76 \%$ destruction of pollutants, but in experiment of $6 \mathrm{~h}$, with $\mathrm{CaO}: \mathrm{SiO}_{2}$ (4:1) as co-milling reagent at $275 \mathrm{rpm}$ speed, PCDD and PCDF reformation was observed. Chen et al. (2017) also observed the reformation of dioxins in milled MSWI fly ash with either $\mathrm{CaO}$ or $\mathrm{CaO}-\mathrm{Al}$ as additives.

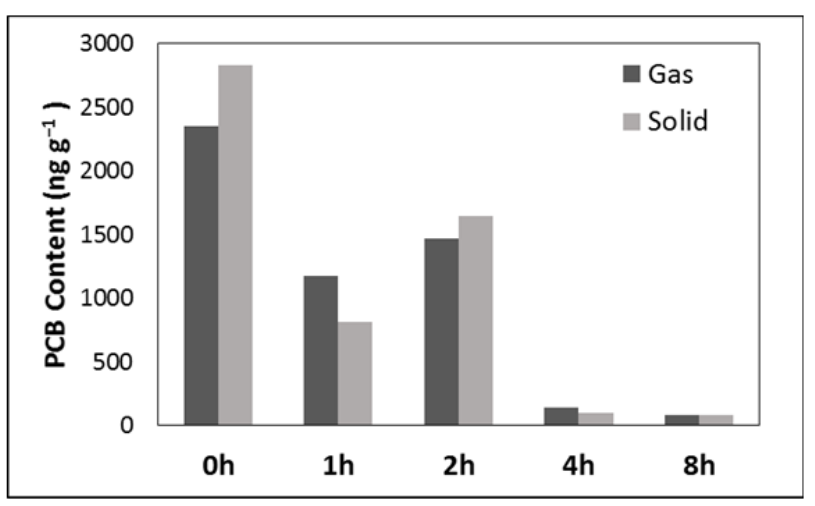

Fig. 1. De novo formation of PCB in gas and solid phase of MFA. 
There are still predecessors (chlorine, unburned carbon and well distributed catalysts) for de novo formation in fly ash and that could be attributed to the reformation of PCB after milling, and mechanical energy serves as driven force for reformation reaction. Moreover, attrition of iron from housing of milling pots and balls could influence PCDD/F and PCB formation. If chlorides are present in excess amount in fly ash then milling could cause reverse effects on destruction of dioxins, and also if precursors for PCDD/F are present in fly ash they can react with chlorides to contribute reformation.

\section{Homologue Profiles}

The PCB homologue profiles (present signatures of isomer groups from mono- $\mathrm{CB}$ through deca-CB) in fly ash were analyzed (Fig. 2) and compared to investigate the relationship between them (supplementary data is provided in Tables S4 and S5). Understanding fingerprints from a particular source is a useful tool to find their impact on environment. Overall, lower chlorinated- PCB homologues were dominant, both in gas and in solid phase of MFA. The distribution of isomers from $0 \mathrm{~h}$ milled sample are different, compared to milled samples $(1,2,4$, and $8 \mathrm{~h}$ milled), which means that milling affects the distribution of isomers. Mono- to Penta-CB dominated the homologues of PCB in $0 \mathrm{~h}$ milled MFA, accounting for 76 and $73 \%$ of the total $\mathrm{PCB}$ in gas and solid phase, respectively. The final concentration reduction of aforementioned homologues was more than $99 \%$ in both phases after $8 \mathrm{~h}$ of milling.

Moreover, an understanding of unintentional formation mechanisms for PCB in fly ash could be helpful to guide development of methods for control and reduce PCB levels in the environment (Jiang et al., 2015). A large proportion of unwanted PCB during waste incineration is released in fly ash. All prerequisites (carbon, transition metals and sources of chlorine) for de novo synthesis as well as for dehalogenation reactions (Pekárek et al., 2001) are present in excess in milled samples (see Table S1). Table 1 presents Pearson correlation coefficients $\left(\mathrm{R}^{2}\right)$ to establish mechanistic relationships between the PCB homologue groups (relationship between concentrations of homologue groups). The homologues have fairly high $\mathrm{R}^{2}$ values with adjacent groups, suggesting that chlorination/dechlorination of PCB isomers is also a pathway of PCB formation/ destruction in addition to de novo synthesis which involves oxychlorination and breakdown of carbon in fly ash (Vogg and Stieglitz, 1986). We presume that lower chlorinated biphenyls were formed by de novo synthesis in fly ash (as still generated by milled MFA), while further chlorination of these compounds to form higher chlorinated ones was greatly halted, due to changes in MFA composition.

The degree of chlorination ( $d c$, average number of chlorine substituent) was one of way to judge mechanical treatment effect for de novo formation of PCB $(d c$, calculated by Eq. (S1)). A decreasing trend of $d c$ value was found in MFA samples with milling time and $34 \%$ less chlorine substitution in gas phase and $43 \%$ in solid phase was observed after $8 \mathrm{~h}$ milling, compared to original samples (see Table 2). The dechlorination and destruction potential of PCB from municipal waste incinerators depend on fly ash composition (Weber et al., 2002). Milling brings in attrition of $\mathrm{Fe}$ among other metals and iron metal acts as a

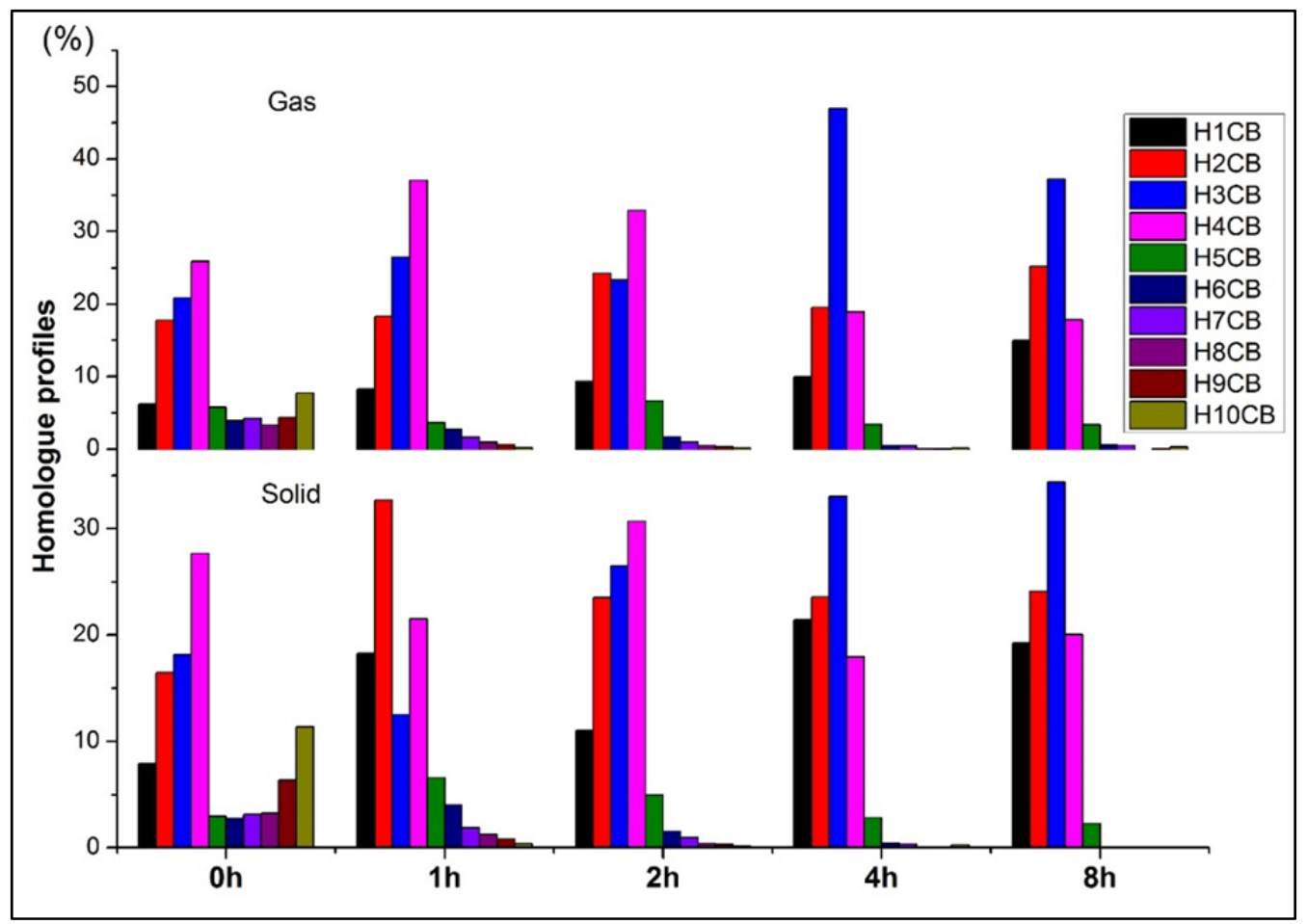

Legends; H1-H10 represent mono- to deca-CB

Fig. 2. PCB homologue profiles at $0,1,2,4$ and $8 \mathrm{~h}$ milled MFA. 
Table 1. Pearson correlation coefficients for the relationships between the polychlorinated biphenyl homologue groups. $\mathrm{CB}=$ chlorinated biphenyl.

\begin{tabular}{|c|c|c|c|c|c|c|c|c|c|}
\hline Gas & Mono-CB & Di-CB & Tri-CB & Tetra-CB & Penta-CB & Hexa-CB & Hepta-CB Octa-CB & Nona-CB & DecaCB \\
\hline Mono-CB & 1 & & & & & & & & \\
\hline Di-CB & 0.990327 & 1 & & & & & & & \\
\hline Tri-CB & 0.971479 & 0.974347 & 1 & & & & & & \\
\hline Tetra-CB & 0.986525 & 0.973341 & 0.991056 & 1 & & & & & \\
\hline Penta-CB & 0.944904 & 0.981149 & 0.948899 & 0.925316 & 1 & & & & \\
\hline Hexa-CB & 0.794775 & 0.842458 & 0.904204 & 0.847075 & 0.886715 & 1 & & & \\
\hline Hepta-CB & 0.689406 & 0.759045 & 0.817885 & 0.741367 & 0.836696 & 0.982953 & 1 & & \\
\hline Octa-CB & 0.64686 & 0.722 & 0.783075 & 0.700953 & 0.808679 & 0.971002 & $0.998297 \quad 1$ & & \\
\hline Nona-CB & 0.59681 & 0.680888 & 0.736725 & 0.647737 & 0.781186 & 0.949344 & 0.9909330 .996792 & 1 & \\
\hline DecaCB & 0.561424 & 0.651665 & 0.702489 & 0.60908 & 0.761299 & 0.930521 & $0.981948 \quad 0.990596$ & 0.99836 & 1 \\
\hline Solid & Mono-CB & Di-CB & Tri-CB & Tetra-CB & Penta-CB & Hexa-CB & Hepta-CB Octa-CB & Nona-CB & DecaCB \\
\hline Mono-CB & 1 & & & & & & & & \\
\hline Di-CB & 0.995531 & 1 & & & & & & & \\
\hline Tri-CB & 0.889923 & 0.927809 & 1 & & & & & & \\
\hline Tetra-CB & 0.916265 & 0.942368 & 0.981147 & 1 & & & & & \\
\hline Penta-CB & 0.98766 & 0.992365 & 0.910327 & 0.906396 & 1 & & & & \\
\hline Hexa-CB & 0.893734 & 0.883958 & 0.808789 & 0.905038 & 0.822014 & 1 & & & \\
\hline Hepta-CB & 0.771837 & 0.777656 & 0.789449 & 0.889112 & 0.69436 & 0.962628 & 1 & & \\
\hline Octa-CB & 0.698098 & 0.70336 & 0.727253 & 0.838179 & 0.610475 & 0.93388 & $0.993849 \quad 1$ & & \\
\hline Nona-CB & 0.653377 & 0.663002 & 0.710616 & 0.819827 & 0.566295 & 0.906509 & $0.985521 \quad 0.9974$ & 1 & \\
\hline DecaCB & 0.632115 & 0.643026 & 0.698906 & 0.808237 & 0.544574 & 0.893687 & $\begin{array}{lll}0.980271 & 0.994892 \\
\end{array}$ & 0.999566 & 1 \\
\hline
\end{tabular}

Table 2. $d l$-PCB, I-TEQ concentration and Cl-PCB of $0,1,2,4$ and $8 \mathrm{~h}$ milled samples.

\begin{tabular}{|c|c|c|c|c|c|c|c|c|c|c|}
\hline \multirow{3}{*}{ Time, $\mathrm{h}$} & \multicolumn{10}{|c|}{$d l$-PCB concentration $\left(\mathrm{ng} \mathrm{g}^{-1}\right)$} \\
\hline & \multicolumn{5}{|c|}{ gas } & \multicolumn{5}{|c|}{ solid } \\
\hline & $0 \mathrm{~h}$ & $1 \mathrm{~h}$ & $2 \mathrm{~h}$ & $4 \mathrm{~h}$ & $8 \mathrm{~h}$ & $0 \mathrm{~h}$ & $1 \mathrm{~h}$ & $2 \mathrm{~h}$ & $4 \mathrm{~h}$ & $8 \mathrm{~h}$ \\
\hline Tetra-CB (\#81) & 1.4 & 11.2 & 1.0 & 0.1 & 0.0 & 1.6 & 9.4 & 1.2 & 0.0 & 0.3 \\
\hline Tetra-CB (\#77) & 6.2 & 3.4 & 5.5 & 0.3 & 0.2 & 7.4 & 9.6 & 5.9 & 0.4 & 0.1 \\
\hline Penta-CB (\#123) & 2.3 & 0.7 & 2.5 & 0.1 & 0.0 & 0.9 & 0.8 & 0.8 & 0.0 & ${ }^{a}$ n.d \\
\hline Penta-CB (\#118) & 20.0 & 2.3 & 13.5 & 0.7 & 0.5 & 9.0 & 2.6 & 9.0 & 0.4 & n.d \\
\hline Penta-CB (\#114) & 0.1 & 0.4 & 0.4 & 0.0 & 0.0 & 4.3 & 0.5 & 0.5 & 0.0 & 0.0 \\
\hline Penta-CB (\#105) & 8.9 & 2.1 & 2.8 & 0.1 & 0.1 & 5.6 & 2.6 & 8.3 & 0.1 & 0.2 \\
\hline Penta-CB (\#126) & 15.9 & 3.5 & 4.3 & 0.1 & 0.0 & 18.7 & 3.7 & 5.0 & 0.1 & 0.1 \\
\hline Hexa-CB (\#167) & 4.8 & 1.0 & 0.6 & 0.0 & 0.0 & 4.3 & 1.0 & 0.8 & 0.0 & n.d \\
\hline Hexa-CB (\#156) & 11.4 & 2.4 & 1.8 & 0.1 & 0.0 & 12.1 & 2.5 & 2.0 & 0.0 & n.d \\
\hline Hexa-CB (\#157) & 5.8 & 1.5 & 0.9 & 0.0 & 0.0 & 6.1 & 1.3 & 1.1 & 0.0 & n.d \\
\hline Неха-CB (\#169) & 6.9 & 1.5 & 1.0 & 0.0 & 0.0 & 11.8 & 1.5 & 1.1 & 0.0 & n.d \\
\hline Hepta-CB (\#189) & 15.1 & 1.4 & 1.3 & 0.1 & 0.0 & 22.2 & 1.1 & 1.4 & 0.0 & n.d \\
\hline Sum $12 d l$-PCB, ng g $^{-1}$ & 98.9 & 31.3 & 35.7 & 1.6 & 1.0 & 104 & 36.7 & 37.1 & 1.3 & 0.8 \\
\hline${ }^{\mathrm{b}}$ WHO-TEQ, ng TEQ $\mathrm{g}^{-1}$ & 0.8 & 0.1 & 0.7 & 0.0 & 0.0 & 0.4 & 0.2 & 0.4 & 0.0 & 0.0 \\
\hline$d c(\mathrm{Cl}-\mathrm{PCB})$ & 4.3 & 3.3 & 3.2 & 2.9 & 2.8 & 4.6 & 3.0 & 3.1 & 2.6 & 2.6 \\
\hline
\end{tabular}

${ }^{\mathrm{a}}$ n.d $=$ not detected.

${ }^{\mathrm{b}}$ TEQ values were calculated using WHO-TEF (Van den Berg, 2006).

reducing agent to transform contaminants, yet unlike a catalyst, it is consumed in the process (Comba et al., 2011). However these findings need further assessment with regard to chlorination/dechlorination mechanisms in milled samples in context of catalytic metals.

\section{dl-PCB Concentrations}

Table 2 presents the sum of $d l$-PCB and the PCB-related WHO-TEQ-contribution of these $12 d l$-PCB as present in the original MFA and in the milled samples treated at different time. The physical concentration of the sum of $d l$ PCB for gas and solid phase was 98.9 and $104 \mathrm{ng} \mathrm{g}^{-1}$ in original sample, respectively, and this value dropped with increasing milling time, down to $31.3 \mathrm{ng} \mathrm{g}^{-1}(+68 \%)$ in gas and to $36.7 \mathrm{ng} \mathrm{g}^{-1}(+65 \%)$ in solid phase after $1 \mathrm{~h}$ of milling. It demonstrates that $1 \mathrm{~h}$ of milling largely reduced MFA potential for de novo formation of toxic PCB, similar results were obtained with $2,3,7,8-\mathrm{PCDD} / \mathrm{F}$ and $d l$-PCB output during de novo tests of MFA in our previous work (Mubeen et al., 2017). However, further milling of MFA 
for $2 \mathrm{~h}$ slightly raised sum $d l$-PCB concentration to $35.7 \mathrm{ng} \mathrm{g}^{-1}(-14.1 \%)$ in gas phase and to $37.1 \mathrm{ng} \mathrm{g}^{-1}$ $(-1.09 \%)$ in solid phase. Same factors (well mixed samples, better dispersed catalytic metals, carbon and chlorine) as described above, could influence marginally higher reactivity of fly ash. Moreover, the reformation of certain PCB isomers can be explained by hot-spot theory and the presence of $\mathrm{Cu}$ catalyst (most potent catalyst) in $\mathrm{MC}$ treated fly ash. During $\mathrm{MC}$ treatment, when a ball hits another ball or milling pots wall, it compress a small amount of powder and on the contact surface temperature rises up to thousands of $\mathrm{K}$ in a microscopic area $\left(\sim 1 \mu \mathrm{m}^{2}\right)$ for a very short time $\left(\sim 10^{-9} \mathrm{~s}\right)$. Near the contact area the temperature increase is less and last longer. Under these favourable conditions some PCB isomers reformation could occur (Urakaev and Boldyrev, 2000).

The World Health Organization (WHO) toxic equivalence factors (TEFs) were used for calculating the WHO-TEQ contributions for PCB (Van den Berg et al., 2006). WHOTEQ concentration after $8 \mathrm{~h}$ treatment, compared to original sample $(0 \mathrm{~h})$ dropped to $98.0 \%$ in gas and to $99.9 \%$ in solid phase, respectively. Similarly, concentration of total $d l$-PCB was markedly reduced to $99 \%$ both in gas and solid phase. Reduced de novo activity of MFA based on TEQ values showed an increasing tendency with longer milling treatment and reactivity loss of MFA could also attributed to physical and structural changes in fly ash particles, a typical effect of ball milling on treated materials (Baláž et al., 2013).

Comparable isomer distributions of $d l$-PCB were observed in all MFA samples. Four isomers, i.e., Penta-CB (\#118), Penta-CB (\#126), Hexa-CB (\#156), and Hepta-CB (\#189) led these distributions $\left(62 \%\right.$ of the $\sum d l-\mathrm{PCB}$, both in gas and solid). All the four were markedly larger in the original sample than in the milled ones and showed a decreasing tendency with longer treatment time. Penta-CB (\#123), Penta-CB (\#118), Hexa-CB (\#167), Hexa-CB (\#156), Hexa-CB (\#157), Hexa-CB (\#169), and Hepta-CB (\#189) were not detected in solid phase after $8 \mathrm{~h}$ treatment, while, Tetra-CB (\#81) raised from 0.0 to $0.3 \mathrm{ng} \mathrm{g}^{-1}$ in $8 \mathrm{~h}$ milled sample, compared to $4 \mathrm{~h}$ milled one.

\section{Relationship of Milling with De novo Activity}

Table 3 shows Pearson correlation coefficients for selected observations in MFA samples, data is provided in supplementary materials (see Table S6). PCDD/F values were also obtained in same samples and detail results have been presented elsewhere (Mubeen et al., 2017). A fair positive correlation was found between PCB, PCDD/F, Cl-PCB, I-TEQs of corresponding PCB, C, Cl, and average particle size $(d p)$. While with same trend, a negative relationship was found with BET. Interestingly, increased dispersion of catalytic metals $(\mathrm{Cu}, \mathrm{Fe}, \mathrm{Cr}$ and $\mathrm{Ni})$ showed a high negative correlation, this means although dispersion/percentage has increased with milling but authors believe that these metals perhaps lost a particular lattice structure necessary for their catalytic role to carry out de novo activity. The strong negative correlation between metals and PCDD/F could also be elucidated by the fact that alkali metals aid in reductive dechlorination process in the presence of $\mathrm{H}$ donors (Birke et al., 2004) and $\mathrm{SiO}_{2}$ act as a neutral reagent generating

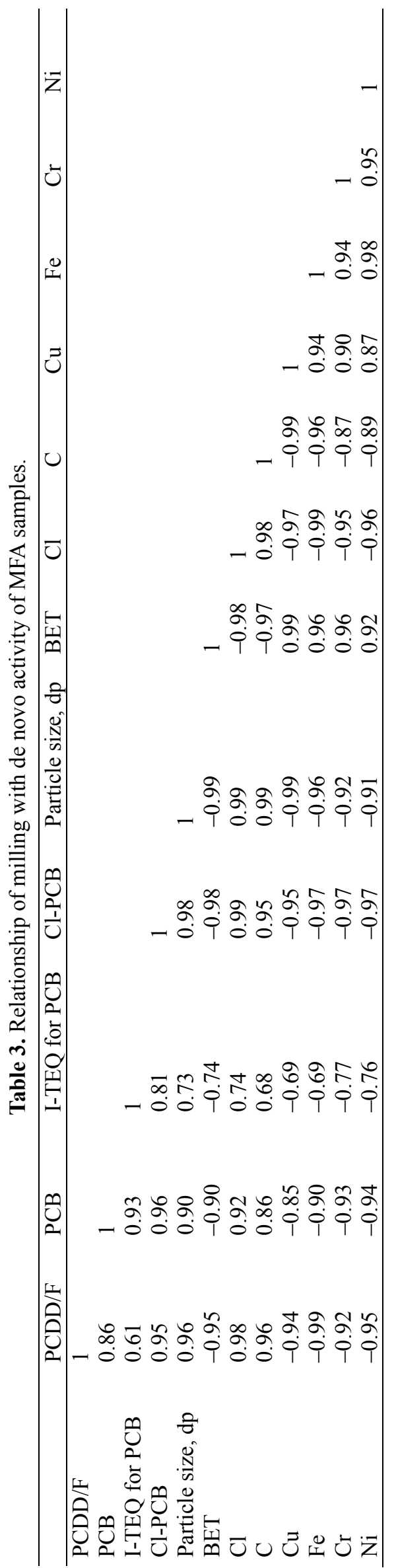


free radicals or fractured surfaces with oxidizing centres. $\mathrm{SiO}_{2}$ is a former of surface plasma and can be utilized to decontaminate all kind of organic materials ranged from methane to organohalogens by complete mineralization (Kaupp, 2009). However, at the moment this matter still needs work to study lattice structure of metals in milled samples.

\section{Resulting Isomer Patterns of Milled Samples}

As MC treatment brings in many changes in composition of MFA therefore a systematic evaluation of fingerprints could be helpful in tracking such effects in treated samples. The isomers for $\mathrm{H} 10 \mathrm{CB}, \mathrm{N} 9 \mathrm{CB}, \mathrm{O} 8 \mathrm{CB}$, and $\mathrm{H} 7 \mathrm{CB}$ patterns surviving the tests are given in Fig. 3 (sum of gas and solid phase) and distribution of isomers within homologues varied with milling treatment. An erratic reformation of certain isomers was found (e.g., \#184 and \#207). Isomers \#209 markedly decreased in concentration from 505 to $6 \mathrm{ng} \mathrm{g}^{-1}$ ( $+99 \%$ ) after $1 \mathrm{~h}$ and to $4 \mathrm{ng} \mathrm{g}^{-1}$ after $2 \mathrm{~h}$ treatment, and was ultimately not detected in 4 and $8 \mathrm{~h}$ milled samples. Weber et al. (2002) observed dechlorination at 3- and 4positions of deca-CB, but the ratio of resulting isomers (\#206, \#207 and \#208) obtained in present work is different at each selected milling time, so authors believe that dechlorination is of minor importance in low yield of \#209 in milled samples.

A complete data set representing percent isomer profile with average, minimum, maximum, and standard deviation (\%) over five MFA samples (0, 1, 2, 4 and $8 \mathrm{~h}$ milled) to verify internal distribution is recorded in supplementary materials (see Table S7). Out of 209 isomers scrutinized in recent analysis, few isomers (e.g., \#12, \#30,\#43, \#50, \#54, $\# 59, \# 74)$ were not detected in any case $(0,1,2,4$, and $8 \mathrm{~h}$ milled MFA). However, \#64 and \#68 dominated the list with $10 \%$ distribution in $0 \mathrm{~h}$ MFA, followed by \#209 and \#11 isomers with 9 and 7\% distribution among 209 isomers, respectively. Further, average value of individual isomers over five selected milling times, was observed in a range between $<0$ (\#34, \#39, \#55, \#57, \#58, \#67, \#79, \#135,
\#148) to 57 (\#206) and RSD (\%) values between 9\% (\#28 and \#31) to $149 \%$ (\#98, \#102 and \#121), leaving a span of almost 16 . Based on RSD values, most variable $d l$-PCB isomers were \#81 (133\%), followed by \#114 (90\%) and \#126 (81\%), while less variable isomer was \#105 (22\%).

Tables S8(a) and S8(b) records percent reduction efficiencies (calculated by Eq. (S2)) of PCB isomers in gas and solid phase of MFA for $1,2,4$, and $8 \mathrm{~h}$ of milling, compared to non-milled sample $(0 \mathrm{~h})$. At the end of treatment $(8 \mathrm{~h})$, erratic reformation of some mono- to penta-CB isomers was observed in solid phase (range, $-14.7 \%$ to $-1296.6 \%$ ) with penta-CB leading the list, while in gas phase less reformation was observed towards the end of treatment (range, $0.1 \%$ to $-9.6 \%$ ). Fig. 4 shows percent reduction/increased efficiency of $d l$-PCB in gas and solid phase of MFA. After $2 \mathrm{~h}$ milling, dominant reformation of \#118 (-488.2) followed by \#123 (-255.8) and \#77 (-60.4) were observed in gas phase, while \#118 (-244.7) and \#105 (-222.5) were dominant isomers in solid phase. Isomer \#81 immediately rose in concentration $(-718 \%$ in gas and $-486 \%$ in solid phase, respectively) after $1 \mathrm{~h} \mathrm{MC}$ treatment compared to original sample and ultimately reduced to $90 \%$ and $98 \%$ in gas and in solid phase after $2 \mathrm{~h}$ and $4 \mathrm{~h}$ treatment, respectively. Interestingly, \#81 again rose in concentration in $8 \mathrm{~h}$ milled sample. Since composition of MFA is changed with MC treatment, it is difficult to elucidate which particular factor triggered reformation of certain isomers.

The average values of isomers and their large RSD (\%) over five MFA samples suggest that milling effect shows no obvious pattern, rather has a limited impact on their internal distribution.

\section{CONCLUSION}

Mechanical treatment of fly ash brings in many changes, as reduction of average particle size, increased BET surface area, better dispersion of cations and anions, less crystallinity and reduced de novo activity for formation of PCB.

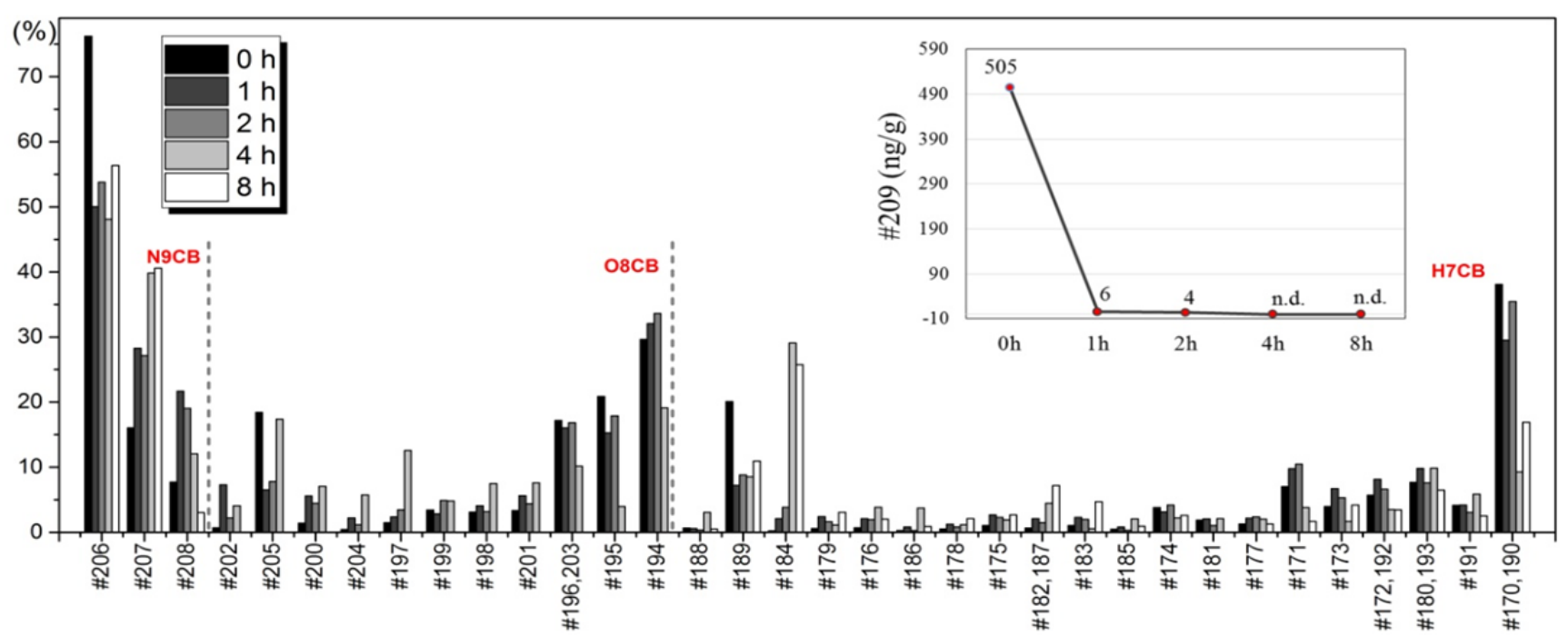

Fig. 3. $\mathrm{PCB}$ isomers (D10CB, N9CB, O8CB and $\mathrm{H} 7 \mathrm{CB})$ in $0,1,2,4$ and $8 \mathrm{~h}$ milled MFA. 


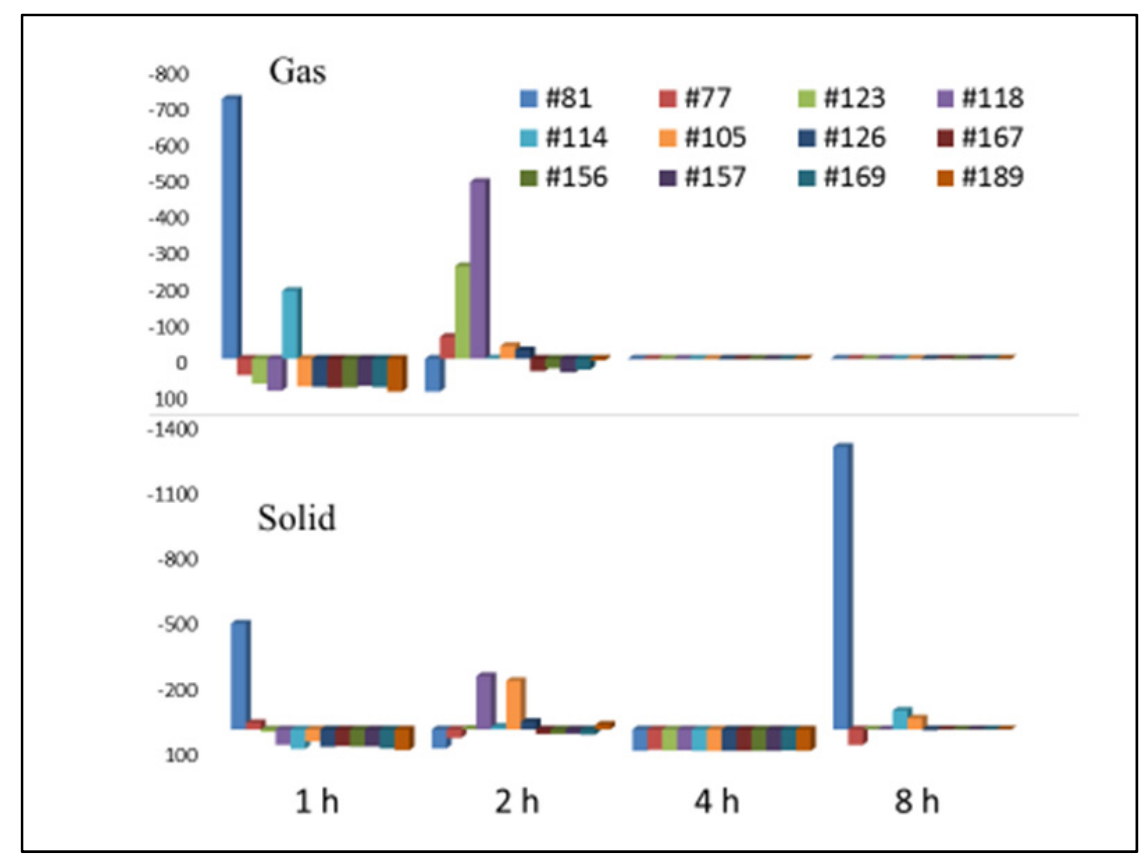

Fig. 4. Percent reduction/increased (+/-) efficiency of $d l$-PCB isomers in 1, 2, 4 and $8 \mathrm{~h}$ MFA compared to zero-milled sample $(0 \mathrm{~h})$.

$\sum \mathrm{PCB}$ in original sample $(0 \mathrm{~h})$ was found in substantial amount both in gas and in solid phase of MFA, and $1 \mathrm{~h}$ milled fly ash produced $50 \%$ less PCB in gas and $71 \%$ less in solid phase, respectively. Interestingly, reformation of biphenyls was observed for the $2 \mathrm{~h}$ milled sample, which ultimately reduced up to $97 \%$ after long $8 \mathrm{~h}$ milling. Similar trend was observed for $\sum$ I-TEQ concentrations in gas and solid phase at $0,1,2,4$, and 8 milling hours and $99 \%$ reduction of $\sum \mathrm{I}-\mathrm{TEQ}$ in MFA was achieved after $8 \mathrm{~h}$. Milling treatment also affected average chlorination degree, as observed $d c$ value in $0 \mathrm{~h}$ milled sample is different compared to milled samples $(1,2,4$, and $8 \mathrm{~h})$. Dechlorination seems to be a part of factors for very low output of high chlorinated isomer of PCB in milled samples.

Sum of $12 \mathrm{dl}$-PCB isomers also showed similar trend with milling treatment time, but only a marginal reformation was observed after $2 \mathrm{~h}$, which further reduced to a great extent in $8 \mathrm{~h}$ treated sample. Isomers from mono- to decaCB showed no particular pattern and distribution was found variable with prolonged milling. An erratic reformation of certain isomers was found, including $\mathrm{dl}$-PCB isomers.

These results reveal that as a promising green technology, MC treatment despite of destruction of POPs, is also a good method to control pollutants for long term disposal or reuse. However, due to the various unexpected results and experimental limitations, future studies will try to focus on controlling reformation of PCB by changing experimental conditions, milling speed, milling material, ball to powder ratio, etc.

\section{ACKNOWLEDGEMENTS}

This Project was supported by the national key research and development of China (2017YFC0703100), the
National Natural Science Foundation of China (51706201), the Fundamental Research Funds for the Central Universities (2019FZA4010), and the Program of Introducing Talents of Discipline to University (B08026) and the Zhejiang University's Pao Yu-Kong International Fund.

\section{SUPPLEMENTARY MATERIAL}

Supplementary data associated with this article can be found in the online version at http://www.aaqr.org.

\section{REFERENCES}

Baláž, P., Achimovičová, M., Baláž, M., Billik, P., Cherkezova-Zheleva, Z., Criado, J.M., Delogu, F., Dutková, E., Gaffet, E., Gotor, F.J., Kumar, R., Mitov, I., Rojac, T., Senna, M., Streletskii, A. and WieczorekCiurowa, K. (2013). Hallmarks of mechanochmistry: from nanoparticles to technology. Chem. Soc. Rev. 42: 7571-7637. doi: 10.1039/C3CS35468G.

Birke, V., Mattik, J. and Runne, D. (2004). Mechanochemical reductive dehalogenation of hazardous polyhalogenated contaminants. J. Mater Sci. 39: 5111-5116. doi: 10.1023\%2FB\%3AJMSC.0000039 192.61817.dd.

Cagnetta, G., Hassan, M.M., Huang, J., Yu, G. and Weber, R. (2016a). Dioxins reformation and destruction in secondary copper smelting fly ash under ball milling. Sci. Rep. 6: 22925. doi: 10.1038/srep22925.

Cagnetta, G., Robertson, J., Huang, J., Zhang, K. and Yu, G. (2016b). Mechanochemical destruction of halogenated organic pollutants: A critical review. J. Hazard. Mater. 313: 85-102. doi: 10.1016/j.jhazmat.2016.03.076.

Chen, Z., Lu, S., Mao, Q., Buekens, A., Chang, W., Wang, 
X. and Yan, J. (2016). Suppressing heavy metal leaching through ball milling of fly ash. Energies 9: 524 . doi: 10.3390/en9070524.

Chen, Z., Mao, Q., Lu, S., Buekens, A., Xu, S., Xu, W. and Yan, J. (2017). Dioxins degradation and reformation during mechanochemical treatment. Chemosphere 180: 130-140. doi: 10.1016/j.chemosphere.2017.04.004.

Chen, Z., Tang, M., Lu, S., Ding, J., Qui, Q., Wang, Y. and Yan, J. (2018). Evolution of PCDD/F-signatures during mechanochemical degradation in municipal solid waste incineration filter ash. Chemosphere 208: 176-184. doi: 10.1016/j.chemosphere.2018.05.161.

Cheruiyot, N.K., Lee, W.J., Yan, P., Mwangi, J.K., Wang, L.C., Gao, X., Lin, N.H. and Chang-Chien, G.P. (2016). An Overview of $\mathrm{PCDD} / \mathrm{F}$ inventories and emission factors from stationary and mobile sources: What we know and what is missing. Aerosol Air Qual. Res. 16: 2965-2988. doi: 10.4209/aaqr.2016.10.0447.

Comba, S., Di-Molfetta, A. and Sethi, R. (2011). A comparison between field applications of nano-, micro-, and millimetric zero-valent iron for the remediation of contaminated aquifers. Water Air Soil Pollut. 215: 595607. doi: 10.1007/s11270-010-0502-1.

Deng, D., Qiao, J., Liu, M., Kołodyńska, D., Zhang, M., Dionysiou, D.D., Jua, Y., Mag, J. and Chang, M.B. (2019). Detoxification of municipal solid waste incinerator (MSWI) fly ash by single-mode microwave (MW) irradiation: Addition of urea on the degradation of Dioxin and mechanism. J. Hazard. Mater. 369: 279289. doi: 10.1016/j.jhazmat.2019.01.001.

Dubinskaya, A.M. (1999). Transformations of organic compounds under the action of mechanical stress. Russ. Chem. Rev. 68:637-652. doi: 10.1070/RC1999v068n08A BEH000435.

Guo, C.J., Wang, M.S., Lin, S.L., Mi, H.H., Wang, L.C. and Chang-Chien, G.P. (2014). Emissions of PCDD/Fs and PCBs during the cold start-up of municipal solid waste incinerators. Aerosol Air Qual. Res. 14: 15931604. doi: 10.4209/aaqr.2014.06.0118.

Hu, B., Huang, Q., Bourtsalas, A.C.T., Ali, M., Chi, Y. and Yan, J. (2017). Effect of chlorine on the structure and reactivity of char derived from solid waste. Energy Fuels 31: 7606-7616. doi: 10.1021/acs.energyfuels.7b01042.

Jiang, X., Liu, G., Wang, M. and Zheng, M. (2015). Formation of polychlorinated biphenyls on secondary copper production fly ash: Mechanistic aspects and correlation to other persistent organic pollutants. Sci. Rep. 5: 13903. doi: 10.1038/srep13903.

Kaupp, G. (2009). Mechanochemistry: The varied applications of mechanical bond-breaking. CrystEngComm 11: 388-403, doi: 10.1039/B810822F.

Lee, Y.Y., Hou, W.C., Zhu, J. and Wang, W. (2018). Atmospheric (dry + wet) deposition of PCDD/Fs in Taiwan. Aerosol Air Qual. Res. 18: 2788-2800. doi: 10.4209/aaqr.2018.10.0363.

Liu, G., Yang, L., Zhan, J., Zheng, M., Li, L., Jin, R. and Zhao, Y. (2016). Concentrations and patterns of polychlorinated biphenyls at different process stages of cement kilns co-processing waste incinerator fly ash.
Waste Manage. 58: 280-286. doi: 10.1016/j.wasman.20 16.09.010.

Liu, G.R., Zheng, M.H., Cai, M.W., Nie, Z.Q., Zhang, B., Liu, W.B., Du, B., Dong, S.J., Hu, J.C. and Xiao, K. (2013). Atmospheric emission of polychlorinated biphenyls from multiple industrial thermal processes. Chemosphere 90: 2453-2460. doi: 10.1016/j.chemosphe re.2012.11.008.

Liu, H.Q., Liu, F., Wei, G.X., Zhang, R. and Zhu, Y.W. (2017). Effects of surfactants on the removal of carbonaceous matter and dioxins from weathered incineration fly ash category: Control techniques and strategy. Aerosol Air Qual. Res. 17: 2338-2347. doi: 10.4209/aaqr.2017.08.0266.

Liu, H.Q., Zeng, T.T., Wei, G.X., Zhang, R., Liu, F. and Wang, H. (2018). Comparison of dioxin destruction in the fly ash and froths under microwave irradiation. Aerosol Air Qual. Res. 19: 925-936. doi: 10.4209/aaqr.2 018.09.0337.

McKay, G. (2002). Dioxin characterisation, formation and minimisation during municipal solid waste (MSW) incineration: review. Chem. Eng. J. 86: 343-368. doi: 10.1016/S1385-8947(01)00228-5.

Mubeen, I., Lin, X., Buekens, A., Cao, X., Lu, S., Tang, M. and Yan, J. (2017). PCDD/F formation in milled fly ash: Metal chloride catalysis. Aerosol Air Qual. Res. 17: 2858-2866. doi: 10.4209/aaqr.2017.08.0279.

Nie, Z., Liu, G., Liu, W., Zhang, B. and Zheng, M. (2012). Characterization and quantification of unintentional POP emissions from primary and secondary copper metallurgical processes in China. Atmos. Environ. 57: 109-115. doi: 10.1016/j.atmosenv.2012.04.048.

Pekárek, V., Grabic, R., Marklund, S., Punčochář, M. and Ullrich, J. (2001). Effects of oxygen on formation of $\mathrm{PCB}$ and PCDD/F on extracted fly ash in the presence of carbon and cupric salt. Chemosphere 43:777-782. doi: 10.1016/S0045-6535(00)00433-1.

Praipipat, P., Rodenburg, L.A. and Cavallo, G.J. (2013). Source apportionment of polychlorinated biphenyls in the sediments of the Delaware River. Environ. Sci. Technol. 47: 4277-4283. doi: 10.1021/es400375e.

Praipipat, P. (2014). Source apportionment of polychlorinated biphenyls in New Jersey air and Delaware River sediments, Doctoral thesis, Rutgers University-Graduate School-New Brunswick. http://www.library.canterbury.ac. nz/services/ref/apa/thesis.shtml.

Sakai, S., Hiraoka, M., Takeda, N. and Shiozaki, K. (1993). Coplanar PCBs and PCDDs/PCDFs in municipal waste incineration. Chemosphere 27: 233-240. doi: 10.1016/0 045-6535 (93)90297-I.

Sakai, S., Hiraoka, M., Takatsuki, H. and Kawakami, I. (2001). Dioxin like PCBs released from waste incineration and their deposition flux. Environ. Sci. Technol. 35: 3601-3607. doi: 10.1021/es001945j.

Stieglitz, L. (1998). Selected topics on the de novo synthesis of PCDD/PCDF on fly ash. Environ. Eng. Sci. 15: 5-18. doi: 10.1089/ees.1998.15.5.

Tang, H., Cui, K., Xing, J., Zhu, J., Lee, W.J., Mwangi, J.K. and Lee, Y.C. (2017). Part I: PM $^{2.5}$ and polychlorinated 
dibenzo- $p$-dioxins and dibenzofurans (PCDD/Fs) in the ambient air of southern China. Aerosol Air Qual. Res. 17: 1550-1569. doi: 10.4209/aaqr.2017.03.0117.

U.S. EPA (2008). Method 1668B: Chlorinated biphenyl congeners in water, soil, sediment, biosolids, and tissue by HRGC/HRMS, USEPA. U.S. EPA Press, Washington.

UNEP (2015). Conference of the Parties to the Stockholm Convention. Preliminary assessment of efforts made toward the elimination of polychlorinated biphenyls Report No. UNEP/POPS/COP.7/INF/9, 1-40, UNEP, Geneva, Switzerland.

Urakaev, F.K. and Boldyrev, V.V. (2000). Mechanism and kinetics of mechanochemical processes in comminuting devices: 1. Theory. Powder Technol. 107: 93-107. doi: 10.1016/S0032-5910(99)00175-8.

Van den Berg, M., Birnbaum, L.S., Denison, M., De Vito, M., Farland, W., Feeley, M., Fiedler, H., Hakansson, H., Hanberg, A., Haws, L., Rose, M., Safe, S., Schrenk, D., Tohyama, C., Tritscher, A., Tuomisto, J., Tysklind, M., Walker, N. and Peterson, R.E. (2006). The 2005 World Health Organization re-evaluation of human and mammalian toxic equivalency factors for dioxins and dioxin-like compounds. Toxicol. Sci. 93: 223-241. doi: 10.1093/toxsci/kfl055.

Vogg, H. and Stieglitz, L. (1986). Thermal behavior of $\mathrm{PCDD} / \mathrm{PCDF}$ in fly ash from municipal incinerator. Chemosphere 15: 1373-1378. doi: 10.1016/0045-6535(8 6)90412-1.

Wang, Y.F., Wang, L.C., Hsieh, L.T., Li, H.W., Jiang, H.C., Lin, Y.S. and Tsai, C.H. (2012). Effect of temperature and $\mathrm{CaO}$ addition on the removal of polychlorinated dibenzo- $p$-dioxins and dibenzofurans in fly ash from a medical waste incinerator. Aerosol Air Qual. Res. 12: 191-199. doi: 10.4209/aaqr.2011.06.0079.

Weber, R., Takasuga, T., Nagai, K., Shiraishi, H., Sakurai, T., Matuda, T. and Hiraoka, M. (2002). Dechlorination and destruction of PCDD, PCDF and PCB on selected fly ash from municipal waste incineration. Chemosphere 46: 1255-1262. doi: 10.1016/S0045-6535(01)00268-5.

Wu, J.L., Lin, T.C., Wang, L.C. and Chang-Chien, G.P. (2014). Memory effects of polychlorinated dibenzo- $p$ dioxinand furan emissions in a laboratory waste incinerator. Aerosol Air Qual. Res. 14: 1168-1178. doi: 10.4209/aaqr.2013.05.0179.

Xing, J., Cui, J., Tang, H., Lee, W.J. Wang, L.C. Zhu, J. and Huang, Q. (2017). Part II: $\mathrm{PM}_{2.5}$ and polychlorinated dibenzo- $p$-dioxins and dibenzofurans (PCDD/Fs) in the ambient air of northern China. Aerosol Air Qual. Res. 17: 2010-2026. doi: 10.4209/aaqr.2017.06.0211.

Yan, J., Peng, Z., Lu, S., Li, X., Ni, M., Cen, K. and Dai, H. (2007). Degradation of PCDD/Fs by mechanochemical treatment of fly ash from medical waste incineration. $J$. Hazard. Mater. 147: 652-657. doi: 10.1016/j.jhazmat.2 007.02.073.

Yang, Z., Xia, C., Zhang, Q., Chen, J. and Liang, X. (2007). Catalytic detoxification of polychlorinated dibenzo- $p$-dioxins and polychlorinated dibenzofurans in fly ash. Waste Manage. 27: 588-592. doi: 10.1016/j.was man.2006.02.019.

Zhan, M., Wang, T., Yang, j., Ji, L., Zhou, G., Chen, T., Li, $X$. and Lin, X. (2018). The behaviors and relationships of PCDD/Fs and chlorobenzenes in the whole process of one municipal solid waste incinerator. Aerosol Air Qual. Res. 18: 3134-3146. doi: 10.4209/aaqr.2018.03.0092.

Zhang, W., Wang, H., Huang, J., Yu, M., Wang, F., Zhou, L. and $\mathrm{Yu}, \mathrm{G}$. (2014). Acceleration and mechanistic studies of the mechanochemical dechlorination of HCB with iron powder and quartz sand. Chem. Eng. J. 239: 185-191. doi: 10.1016/j.cej.2013.11.018.

Zhao, Y., Cui, K., Chen, S., Yin, Z., Chao, H.R. and ChangChien, G-P. (2018). Atmospheric $\mathrm{PM}_{2.5}$, total PCDD/FsWHO2005-TEQ level and wet deposition: Cases of Jinan and Weihai cities, China. Aerosol Air Qual. Res. 18: 3081-3095. doi: 10.4209/aaqr.2018.11.0395.

Zhu, J., Tang, H., Xing, J., Lee, W.J., Yan, P. and Cui, K. (2017). Atmospheric deposition of polychlorinated dibenzo- $p$-dioxins and dibenzofurans in two cities of southern China. Aerosol Air Qual. Res. 17: 1798-1810. doi: 10.4209/aaqr.2017.05.0177.

Received for review, April 20, 2019 Revised, July 16, 2019 Accepted, July 17, 2019 